\title{
A Flexible Temperature Sensor for Noncontact Human-Machine Interaction
}

\author{
Shiqi Chen ${ }^{1,+}$, Xiaolong Han ${ }^{2, \dagger}$, Peng Hong ${ }^{1}$, Yue Zhang ${ }^{1,3, *} \mathbb{0}$, Xiangyu Yin ${ }^{3,4, *}$ and Bingwei He ${ }^{1,3}$ \\ 1 College of Mechanical Engineering and Automation, Fuzhou University, Fuzhou 350108, China;

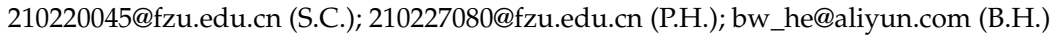 \\ 2 Maynooth International Engineering College, Fuzhou University, Fuzhou 350108, China; 831902106@fzu.edu \\ 3 Fujian Engineering Research Center of Joint Intelligent Medical Engineering, Fuzhou 350108, China \\ 4 College of Chemical Engineering, Fuzhou University, Fuzhou 350108, China \\ * Correspondence: yuezhang@fzu.edu.cn (Y.Z.); xyin65@fzu.edu.cn (X.Y.) \\ + Shiqi Chen and Xiaolong Han contributed equally to this work.
}

Citation: Chen, S.; Han, X.; Hong, P.; Zhang, Y.; Yin, X.; He, B. A Flexible Temperature Sensor for Noncontact Human-Machine Interaction. Materials 2021, 14, 7112. https:// doi.org/10.3390/ma14237112

Academic Editor: Mustafa Yavuz

Received: 22 October 2021

Accepted: 18 November 2021

Published: 23 November 2021

Publisher's Note: MDPI stays neutral with regard to jurisdictional claims in published maps and institutional affiliations.

Copyright: () 2021 by the authors. Licensee MDPI, Basel, Switzerland. This article is an open access article distributed under the terms and conditions of the Creative Commons Attribution (CC BY) license (https:// creativecommons.org/licenses/by/ $4.0 /)$.

\begin{abstract}
Flexible sensors have attracted extensive attention because of their promising applications in the fields of health monitoring, intelligent robots, and electronic skin, etc. During the COVID-19 epidemic, noncontact control of public equipment such as elevators, game consoles, and doors has become particularly important, as it can effectively reduce the risk of cross-infection. In this work, a noncontact flexible temperature sensor is prepared via a simple dip-drying progress, in which poly(3,4-ethylenedioxythiophene):poly(4-styrene sulfonate) (PEDOT:PSS) and printer paper served as the sensing material and the flexible substrate, respectively. We combined the highly sensitive temperature-responsive property of PEDOT:PSS with the good hygroscopicity of printer paper. The prepared sensor shows high sensitivity and good stability in noncontact sensing mode within the temperature range of $20-50{ }^{\circ} \mathrm{C}$. To prove the practicability of the noncontact temperature sensor, a $3 \times 2$ sensing array is prepared as a noncontact human-machine interface to realize the interaction between player and "Pound-A-Mole game" and a Bluetooth car. These two demos show the sensor's ability to perceive nearby temperature changes, verifying its application potential as a noncontact human-machine interaction interface.
\end{abstract}

Keywords: temperature-sensitive; noncontact sensing; flexible sensor

\section{Introduction}

With the continuous development of sensing technology, people have shown great demand for advanced flexible electronic devices [1,2]. Among them, flexible temperature sensors have attracted the attention of many specialists and scholars domestically and abroad in recent years due to their unique properties of high efficiency, seamless contact with the dynamic human body, continuity, and longterm temperature monitoring [3-5]. When heat transfer occurs between the human body and its surrounding things, thermometers with high precision and continuous temperature measurement are often used to monitor the interaction between humans and machines or between humans and the environment. In the field of intelligent medical care, researchers often monitor the patient's body temperature and other physiological parameters to diagnose various diseases [6-8]. In addition, real-time temperature response shows great application prospects in fields such as artificial electronic skin and emotion recognition [9-12]. Thus, it can be said that temperature as a basic physical parameter, as well as being used to monitor physiological activities and health, can be used to monitor and control human-machine interaction [13,14].

Flexible temperature sensors often adopt multi-point ways to continuously measure the surface temperature of irregular objects [15], which requires the sensors to have the following characteristics: (1) The temperature sensing performance in terms of measurement accuracy, sensitivity, response time, and repeatability should be matched with traditional 
thermometers. (2) The flexible sensor should be highly sensitive and have longterm stability in a temperature range of $20^{\circ} \mathrm{C} 500^{\circ} \mathrm{C}$. (3) Facile fabrication on a large scale is also very important for the sensors' application, because multipixel sensing arrays are often integrated to achieve simultaneous measurement of multipoint temperature. (4) Mechanical robustness and anti-interference are also essential for flexible temperature sensors. In practical applications, flexible temperature sensors are often used for dynamic surface temperature measurement. During the measurement, the sensor will be twisted and deformed with the surface, so good mechanical robustness is required to ensure its longterm use [8]. Moreover, the sensitive electrodes of flexible temperature sensors are mostly made of graphene [16], carbon nanotubes [17], and metal nanomaterials [18,19], which are not only highly sensitive to temperature, but also extremely sensitive to strain and pressure, which will cause serious signal crosstalk and make it difficult to distinguish whether the electrical signal changes are determined by temperature or deformation. Therefore, anti-interference is very important to ensure the accuracy of temperature measurement.

Poly(3,4-ethylenedioxythiophene):poly(4-styrene sulfonate) (PEDOT:PSS), an aqueous solution of PEDOT and PSS, has attracted more and more attentions due to its high optical transparency and adequate conductivity (higher than $1 \mathrm{~S} \mathrm{~cm}^{-1}$ ). With the fabrication techniques of inkjet printing [20], direct-print dispensing [21], and dip-drying [22], PEDOT:PSS films can be obtained and be subsequently integrated into flexible electronic devices. In these flexible electronic devices, the PEDOT:PSS films usually serve as active components, because they are sensitive to some environmental factors, such as humidity, $\mathrm{pH}$, and temperature. The resistance of the PEDOT:PSS films will decrease with temperature increasing, humidity decreasing, and $\mathrm{pH}$ increasing. Although many flexible electronics were developed based on PEDOT:PSS, little research has been conducted on their ability as a non-contact interface to control human-machine interaction. In addition, a flat PEDOT:PSS film is usually insensitive to strain and pressure, unless the PEDOT:PSS is prepared on a substrate with good elasticity or special microstructures. Based on these feature, we prepared a flexible temperature-sensitive paper by dipping common flexible printer paper in PEDOT:PSS solution and then drying it. Due to the high sensitivity of the PEDOT:PSS paper to temperature $\left(-21.5 \times 10^{-3}{ }^{\circ} \mathrm{C}^{-1}\right.$ in temperature range of $\left.20-50{ }^{\circ} \mathrm{C}\right)$, the temperature-sensitive paper can quickly detect the proximity of objects with temperature differences, enabling it to identify the human proximity and act as a control interface to achieve noncontact human-machine interaction.

\section{Experiment and Characterization}

\subsection{Materials}

White printer papers with standard quality of $60 \mathrm{~g} \mathrm{~m}^{-2}$ and $80 \mathrm{~g} \mathrm{~m}^{-2}$, and polyethylene terephthalate (PET) film with a thickness of $0.125 \mathrm{~mm}$ were used as flexible substrates after degreasing with acetone, dewatering with ethanol. PEDOT:PSS (1.5 wt.\%) and dimethyl sulfoxide (DMSO) were used as received (Aladdin, Shanghai, China). Deionized water $\left(18.2 \mathrm{M} \Omega \mathrm{cm}^{-1}\right)$ from a Milli-Q system (Human Power I Plus, Korea) was used to prepare all aqueous solutions. Electrical contacts were made using silver paste (SCP003, Electrolube, Leicestershire, UK).

\subsection{Preparation of PEDOT:PSS Temperature Sensor}

The noncontact temperature-sensitive paper was prepared via an easy-to-operate dip-drying progress, in which the printer papers or PET film acted as the flexible substrate, and the PEDOT:PSS acted as temperature-sensitive material. The schematic diagram of the preparation process is shown in Figure 1. Specifically, PEDOT:PSS solution and deionized water with a mass ratio of 2:1 was mixed, then $5.0 \mathrm{wt} . \%$ DMSO was added under magnetic stirring at $600 \mathrm{rpm}$ for $10 \mathrm{~min}$ to obtain a uniformly dispersed homogeneous solution. At the same time, the preprocessed printer papers and PET film were cut into a size of $10 \mathrm{~mm} \times 20 \mathrm{~mm}$, and one side of the printer papers was encapsulated with transparent adhesive tape, so that the solution could only be deposited on one side of the printer papers. 
The flexible substrates were vertically immersed in the above PEDOT:PSS solution for $90 \mathrm{~s}$ and then heated at $100{ }^{\circ} \mathrm{C}$ for $30 \mathrm{~min}$. Finally, temperature sensors were obtained by using conductive silver paste to connect the temperature-sensitive papers/PET with external circuit. Except for special instructions, all experiments were carried out at $28 \pm 1{ }^{\circ} \mathrm{C}$ of temperature and $70 \pm 1 \%$ of relative humidity.

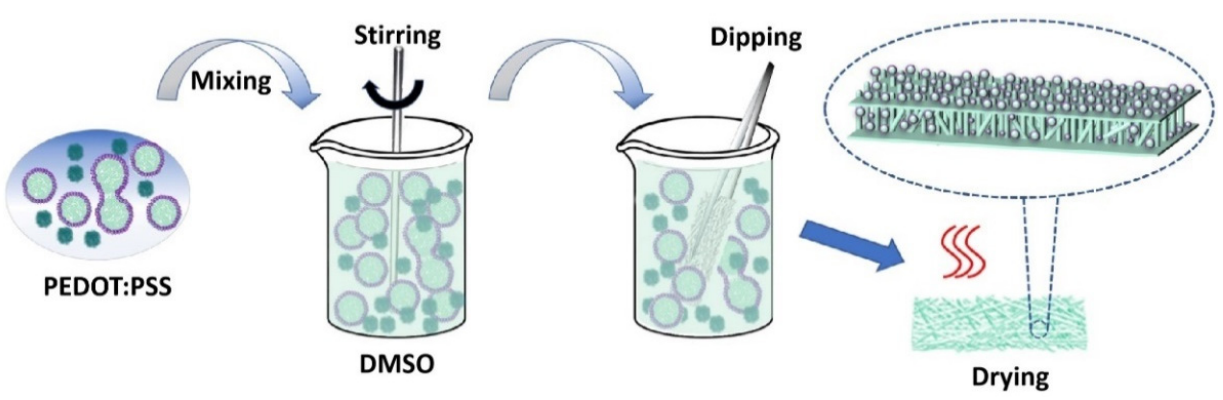

Figure 1. Schematic diagram of the preparation process for flexible temperature sensors.

\subsection{Characterization}

The optical morphology of the commercial printer papers and the fabricated temperature-sensitive papers were characterized using an Optical Microscope (DM750, Leica, Weztlar, Germany). A 3D optical surface profiler was used to map the surface topography and determine surface roughness of the specimens. The cross-sectional morphology of the sensors was determined by FE-SEM tests (Nova NanoSEM 230, FEI, MA, USA). The temperature-sensitive test system includes a DZF-6050 vacuum drying oven (Shanghai Jinghong Experimental Equipment Co., Ltd., Shanghai, China), a DMM6500 digital acquisition system multimeter (KEITHLEY, Cleveland, OH, USA) and a thermocouple thermometer instrument (YET-601, Yuwexa, Guangdong, China). In order to more accurately measure the temperature of the sensor, a thermocouple probe was pasted to the lower surface of the flexible temperature sensors. Then the flexible temperature sensors were placed into a preheated oven and connected to a multimeter (DMM6500, KEITHLEY, $\mathrm{OH}, \mathrm{USA}$ ) to monitor the resistance change. As the temperature rose, the resistance of the sensors was recorded in real-time using a two-wire resistance measurement mode. The measurement frequency was $1 \mathrm{kHz}$, and the tested temperature ranged from 20 to $80^{\circ} \mathrm{C}$. All tests were performed at least five times, and the average value is reported here.

\section{Results and Discussion}

\subsection{Preparation and Characterization}

The temperature-sensitive paper was prepared by a simple dip-drying progress as shown in Figure 1. To study the effect of flexible substrates on the temperature-sensitive property, printer papers with different quality $\left(60 \mathrm{~g} \mathrm{~m}^{-2}\right.$ and $\left.80 \mathrm{~g} \mathrm{~m}^{-2}\right)$ and PET film with a thickness of $125 \mu \mathrm{m}$ were dipped into PEDOT:PSS solution for $90 \mathrm{~s}$, respectively. The characteristics of the PEDOT:PSS film formed on different flexible substrates were observed in detail using an optical microscope. Obviously, the surface of the PET film before and after dipping was very smooth, indicating that the PEDOT:PSS uniformly coats on the PET surface after dipping (Figure 2a). In contrast, the fiber structure of the two paper-based flexible substrates was clearly visible, and the $60 \mathrm{~g} \mathrm{~m}^{-2}$ printer paper had more substantial voids in the fibrous material than the $80 \mathrm{~g} \mathrm{~m}^{-2}$ printer paper, as shown in Figure $2 \mathrm{~b}, \mathrm{c}$. After dipping in PEDOT:PSS solution for $90 \mathrm{~s}$, PEDOT:PSS was deposited on and between paper fibers, but it could not make up for the large-size defects of $60 \mathrm{~g} \mathrm{~m}^{-2}$ printer paper, so incomplete and complete films were formed on the $60 \mathrm{~g} \mathrm{~m}^{-2}$ and $80 \mathrm{~g} \mathrm{~m}^{-2}$ printer papers, respectively. To further judge the deposition of PEDOT:PSS on the three flexible substrates, we conducted a 3D profile observations on the three substrates before and after dipping in PEDOT:PSS solution for $90 \mathrm{~s}$. Figure $2 \mathrm{~d}-\mathrm{f}$ shows that compared with the initial state, the thickness of the three flexible substrates increased after dipping, which 
indicates that PEDOT:PSS successfully deposited on the flexible substrates. Moreover, the more significant change of the paper substrates in thickness and the root mean square roughness $(\mathrm{Rq})$ proves more PEDOT:PSS deposition. In addition, Figure $2 \mathrm{e}, \mathrm{f}$ shows that the initial papers with different qualities have many defects, and the $60 \mathrm{~g} \mathrm{~m}^{-2}$ printer paper is more serious. After depositing PEDOT:PSS, the number and size of the paper defects were significantly reduced, further indicating that a complete conductive film was formed on the paper substrates, which is one of the decisive factors for obtaining uniform temperature-sensitive performance. To future determine the thickness of the PEDOT:PSS film deposited on different substrates, cross-sectional SEM morphology (Figure 2g) and the EDS mapping for elements of $S$ and $C$ (Figure $2 \mathrm{~h}$ ) were carried out. The thickness of the PEDOT:PSS film was $17 \pm 1.2 \mu \mathrm{m}$ on $60 \mathrm{~g} \mathrm{~m}^{-2}$ printer paper, $18 \pm 0.7 \mu \mathrm{m}$ on $80 \mathrm{~g} \mathrm{~m}^{-2}$ printer paper, and $3.5 \pm 0.3 .2 \mu \mathrm{m}$ on FET film.
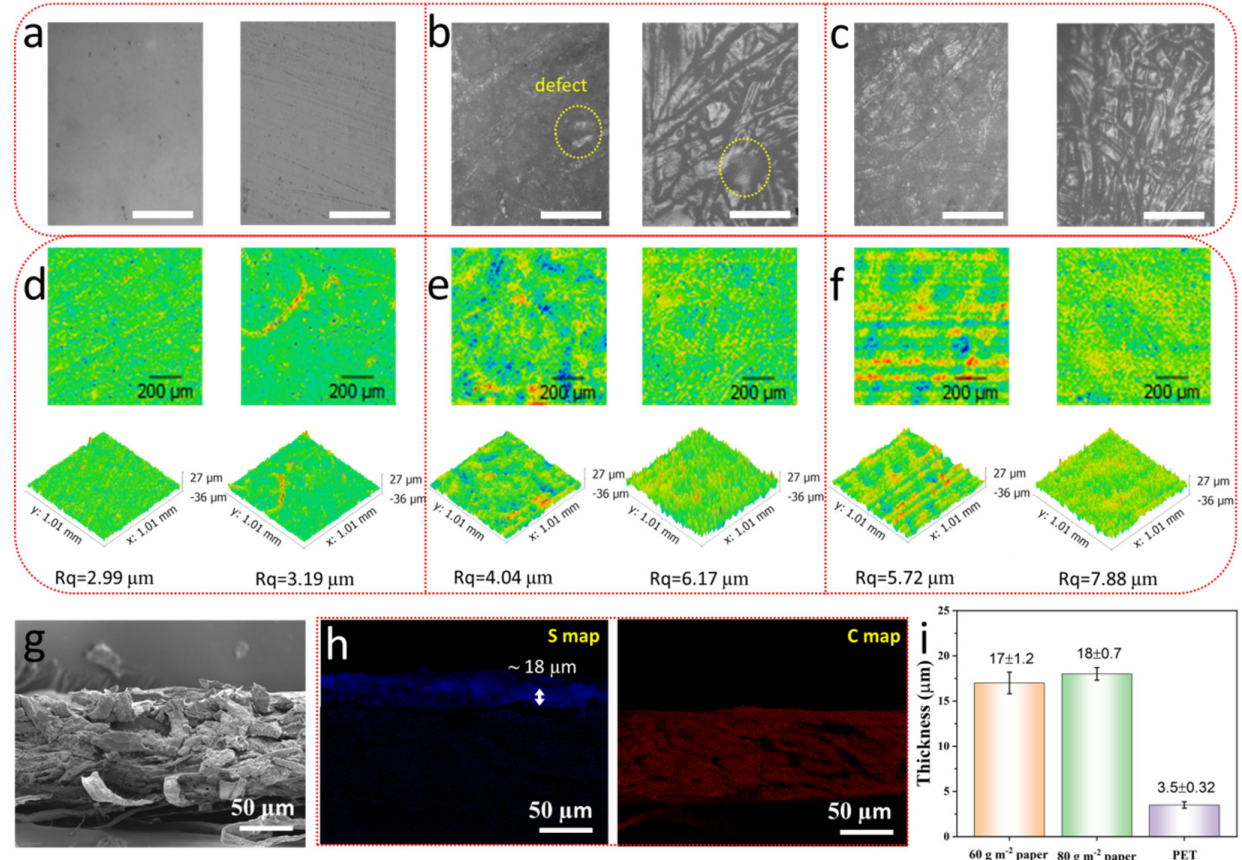

Figure 2. Morphology of PEDOT:PSS film on different flexible substrates. Optical morphology of PEDOT:PSS film prepared on (a) PET film, (b) $60 \mathrm{~g} \mathrm{~m}^{-2}$ printer paper, and (c) $80 \mathrm{~g} \mathrm{~m}^{-2}$ printer paper. Scale bar $=100 \mu \mathrm{m}$. 3D profile of PEDOT:PSS film prepared on (d) PET film, (e) $60 \mathrm{~g} \mathrm{~m}^{-2}$ printer paper, and (f) $80 \mathrm{~g} \mathrm{~m}^{-2}$ printer paper. The left and right images in each figure correspond to the morphology of the initial substrate and the substrate after depositing PEDOT:PSS, Rq is the root mean square roughness. (g) Cross-sectional SEM morphology of the $80 \mathrm{~g} \mathrm{~m}^{-2}$ PEDOT:PSS paper and (h) its EDS mapping for elements of $S$ and C; (i) Thickness of PEDOT:PSS layer on different substrates.

Figure 3a shows the variation curves of normalized resistance $\left(\Delta R / R_{0}\right)$ with respect to temperature for three flexible temperature sensors (the initial resistivity of the $60 \mathrm{~g} \mathrm{~m}^{-2}$, $80 \mathrm{~g} \mathrm{~m}^{-2}$ temperature-sensitive papers and the temperature-sensitive PET are 22.2, 15.1, and $18.9 \mathrm{~m} \Omega \cdot \mathrm{cm}$, respectively, comparable to the value reported in the literature [23,24]). From the curves, the sensitivity of each sensor (Figure $3 b$ ) can be calculated according to the following calculation: $S=\Delta R /\left(R_{0} \cdot \Delta T\right)$, where $R_{0}$ is the initial resistance, $\Delta R$ is the resistance change, and $\Delta \mathrm{T}$ is the temperature change. It can be seen from Figure $3 \mathrm{~b}$ that within the temperature range of $20-80^{\circ} \mathrm{C}$, the sensitivity of the three temperature sensors based on different flexible substrates is sorted as follows: $80 \mathrm{~g} \mathrm{~m}^{-2}$ printer paper $>60 \mathrm{~g} \mathrm{~m}^{-2}$ printer paper $>$ PET film. Obviously, the sensitivity of PET-based sensors is the smallest. In the temperature range of $30-80{ }^{\circ} \mathrm{C}$, its sensitivity is $-9.3 \times 10^{-3}{ }^{\circ} \mathrm{C}^{-1}$, but in $20-30{ }^{\circ} \mathrm{C}$, its temperature sensitivity is only $-1.1 \times 10^{-3}{ }^{\circ} \mathrm{C}^{-1}$, which determines that it cannot be used as a flexible interface to achieve human-machine interaction. At the same time, the sensitivity of the two paper-based sensors showed a higher temperature sensitivity in the 
range of $20-50{ }^{\circ} \mathrm{C}\left(-21.5 \times 10^{-3}{ }^{\circ} \mathrm{C}^{-1}\right.$ for $80 \mathrm{~g} \mathrm{~m}^{-2}$ printer paper, and $-13.8 \times 10^{-3}{ }^{\circ} \mathrm{C}^{-1}$ for $60 \mathrm{~g} \mathrm{~m}^{-2}$ printer paper), and a relatively low sensitivity within the temperature range of $50-80{ }^{\circ} \mathrm{C}$ (Figure $3 \mathrm{~b}$ ). Obviously, the sensitivity of $80 \mathrm{~g} \mathrm{~m}^{-2}$ printer paper was still better than $60 \mathrm{~g} \mathrm{~m}^{-2}\left(-6.2 \times 10^{-3}{ }^{\circ} \mathrm{C}^{-1}\right.$ for $80 \mathrm{~g} \mathrm{~m}^{-2}$ printer paper, and $-4.5 \times 10^{-3}{ }^{\circ} \mathrm{C}^{-1}$ for $60 \mathrm{~g} \mathrm{~m}^{-2}$ printer paper) in the high temperature range, so the $80 \mathrm{~g} \mathrm{~m}^{-2}$ printer paper was selected as the flexible substrate to prepare high-performance temperature sensor.
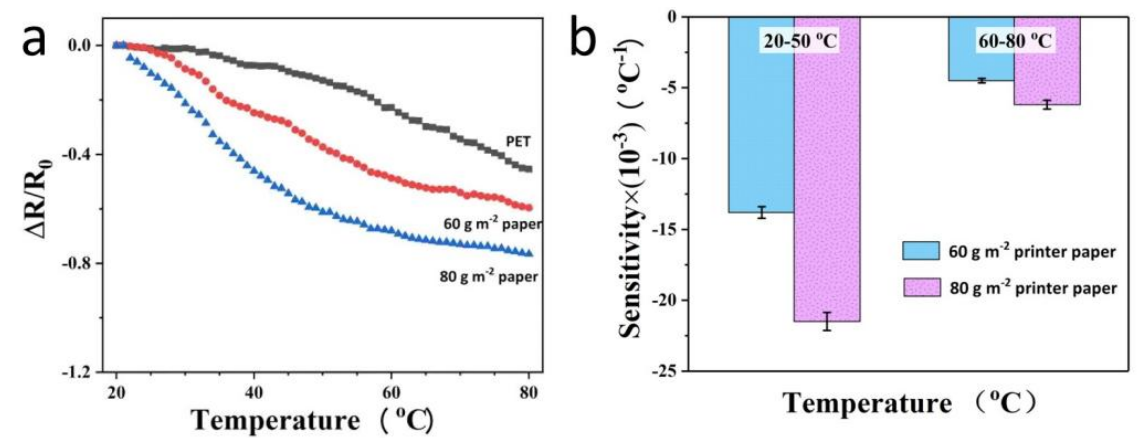

C

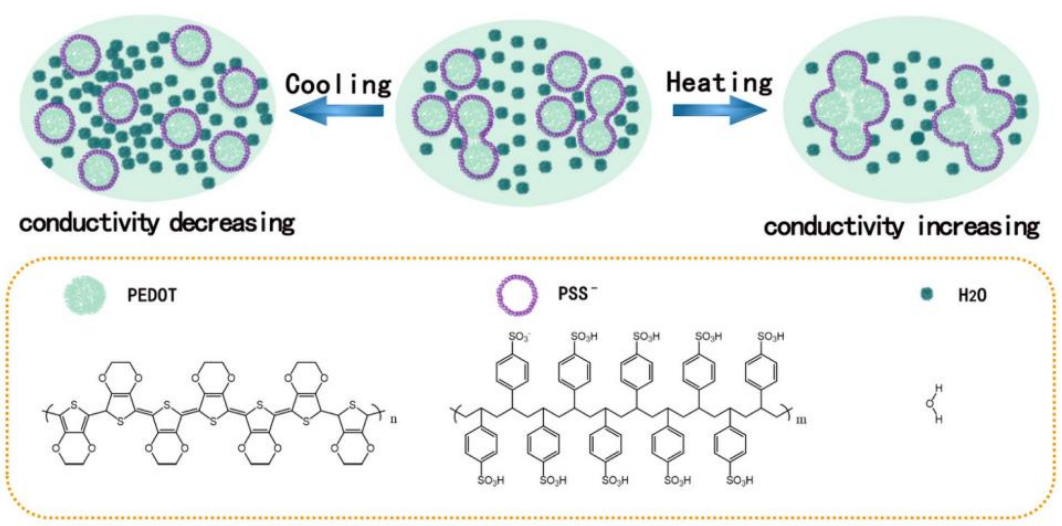

Figure 3. Effect of flexible substrates on sensitivity. (a) Variation curves of the normalized resistance $\left(\Delta R / R_{0}\right)$ with respect to temperature for three flexible temperature sensors; $(b)$ the sensitivity of paper-based sensors within different temperature ranges; (c) schematic diagram of temperature response mechanism for PEDOT:PSS based sensor.

It is known that PEDOT is a black powder with poor water solubility, which is of little use in practical applications. After adding PSS, we could obtain conductive polyelectrolyte complex with improved solubility in aqueous solution. The conductivity of the complex depends on the network characteristics of PEDOT: PSS [25-27] and intermolecular water content (Figure 3c). Increasing the intermolecular water content will reduce the adhesion between the molecules in the PEDOT:PSS network, thereby reducing the conductivity. On the contrary, decreasing the intermolecular water content will increase the conductivity. Heating will inevitably decrease the intermolecular water content in the PEDOT:PSS network, and cooling will play an opposite effect, so the PEDOT:PSS film exhibits temperature-sensitive characteristics. In addition, the high sensitivity of the paper-based sensors compared to the PET-based sensor is also determined by the good moisture absorption of the paper substrates themselves, while the temperature sensitivity of $80 \mathrm{~g} \mathrm{~m}^{-2}$ printer paper is better than that of $60 \mathrm{~g} \mathrm{~m}^{-2}$ printer paper because it has more PEDOT:PSS per unit area. Besides, the denser fibrous structure of the $80 \mathrm{~g} \mathrm{~m}^{-2}$ printer paper plays a more obvious role in absorbing and releasing environmental water molecules. Therefore, in the temperature range of $20-50{ }^{\circ} \mathrm{C}$, the temperature-sensitive property of the $80 \mathrm{~g} \mathrm{~m}^{-2}$ printer paper-based sensor is the best, while PET-based sensor is the worst. In addition, for the paper-based sensors, the influence of temperature over $50{ }^{\circ} \mathrm{C}$ is almost negligible on the intermolecular water content in the PEDOT:PSS network, and under this condition, the 
conductivity of the PEDOT:PSS film depends entirely on the hydrogen bonding of the PSS chains. Undoubtedly, high temperature will activate hydrogen bonds, thereby increasing the adhesion between PEDOT molecules and consequently improving the conductivity of the PEDOT:PSS film. Therefore, in the range of 50 to $80^{\circ} \mathrm{C}$, although the sensitivity of $80 \mathrm{~g} \mathrm{~m}^{-2}$ PEDOT:PSS temperature sensitive paper is lower than that in $20-50{ }^{\circ} \mathrm{C}$, its resistance will still decrease as the temperature increases. For PET-based sensor, due to the poor water absorption of the substrate, temperature mainly determines its electrical conductivity by affecting intermolecular hydrogen bonds. Therefore, its sensitivity in the low temperature region $\left(20-30^{\circ} \mathrm{C}\right)$ is low, and the sensitivity in higher temperature region $\left(30-80^{\circ} \mathrm{C}\right)$ is slightly increased.

Next, we select the $80 \mathrm{~g} \mathrm{~m}^{-2}$ printer paper-based PEDOT:PSS sensor as the research object to investigate the influence of dipping time and the composition of the PEDOT:PSS solution on its temperature-sensitive performance. Firstly, the printer paper with a size of $10 \mathrm{~mm} \times 20 \mathrm{~mm}$ was dipped in the mixture of $1.0 \mathrm{wt} . \%$ PEDOT:PSS $+5.0 \mathrm{wt} . \%$ DMSO for $5,30,60,90,120$, and $150 \mathrm{~s}$ to investigate the effect of dipping time on the performance of the prepared sensors. It can be seen from Figure 4a that with the increase of dipping time, the normalized resistance of the obtained temperature-sensitive papers increases obviously under the same temperature change, proofing its more sensitive temperature-sensing properties. In addition, there is little difference in temperature response of samples dipping for 90 and $120 \mathrm{~s}$. Therefore, we select $90 \mathrm{~s}$ as the best dipping time, and on this basis, we further investigate the influence of the concentration of PEDOT:PSS in the mixed solution on the temperature sensitivity of the samples. Figure $4 \mathrm{~b}$ shows that with the increase of PEDOT:PSS concentration, the sensitivity and stability of the prepared temperature sensor are greatly improved. In the range of $20-50{ }^{\circ} \mathrm{C}$, the sensitivity of temperature-sensitive paper prepared by $1.5 \mathrm{wt} . \%$ and $1.0 \mathrm{wt} . \%$ PEDOT:PSS is $(-23.9 \pm 0.57) \times 10^{-3}{ }^{\circ} \mathrm{C}^{-1}$ and $(-21.5 \pm 0.64) \times 10^{-3}{ }^{\circ} \mathrm{C}^{-1}$, indicating that at this concentrations, PEDOT:PSS can evenly form a film on the printer paper.
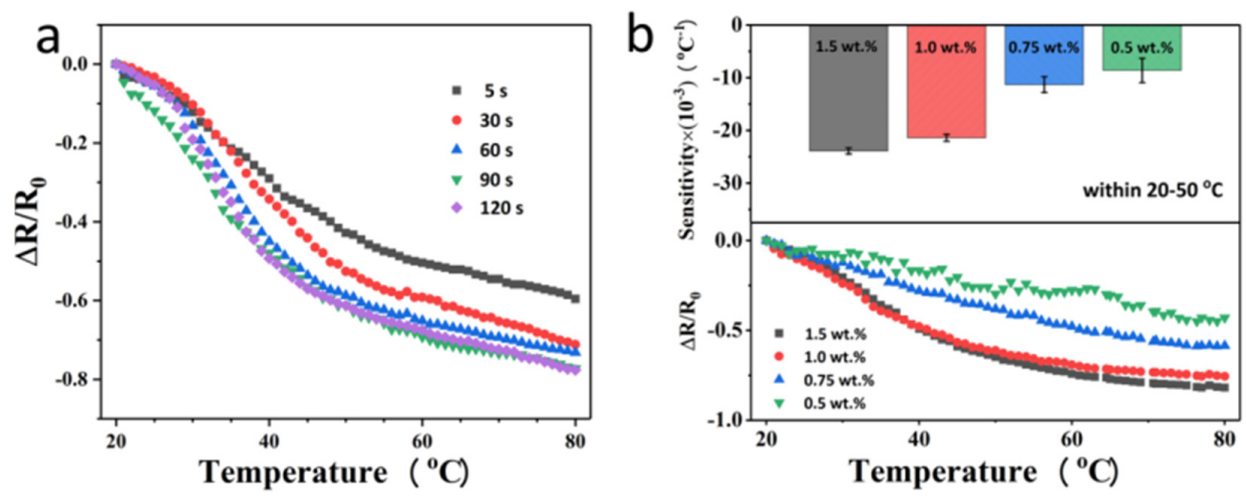

Figure 4. Effect of dipping time and concentration of PEDOT:PSS on the sensitivity of the flexible temperature-sensitive papers. (a) Variation of the normalized resistance $\left(\Delta R / R_{0}\right)$ with respect to temperature for sensing papers prepared with different dipping time; (b) effect of PEDOT:PSS concentration on the sensing properties. Top: Sensitivity of temperature-sensing papers prepared in $0.5,0.75,1.0$, and $1.5 \mathrm{wt}$ \% PEDOT:PSS. Bottom: Variation of the normalized resistance $\left(\Delta \mathrm{R} / \mathrm{R}_{0}\right)$ with respect to temperature for sensing papers prepared in PEDOT:PSS with different concentration. Temperature range: $20-50{ }^{\circ} \mathrm{C}$.

\subsection{Temperature-Sensing Performance}

Based on the above experiments, we prepared flexible temperature-sensing paper by dipping the $80 \mathrm{~g} \mathrm{~m}^{-2}$ printer paper in $1.0 \mathrm{wt} . \%$ PEDOT:PSS + $5.0 \mathrm{wt} . \%$ DMSO mixed solution for $90 \mathrm{~s}$, and investigated its sensing performance. Figure $5 \mathrm{a}$ shows that after the temperaturesensitive paper was repeatedly buckled to $0 \sim-30 \%$ at room temperature 1000 times, the resistance of the sample hardly changed, proving its good mechanical stability and practical applicability. Next, we verified its noncontact sensing performance by controlling the distance between the finger and the temperature-sensitive paper at ambient temperature $\left(28^{\circ} \mathrm{C}\right)$. During the tests, the finger approached the sensor paper to a fixed distance of 1,3, and $5 \mathrm{~mm}$ 
and started recording resistance changes after $10 \mathrm{~s}$. Each distance was maintained for $10 \mathrm{~s}$ to investigate the resistance stability of the temperature-sensitive paper. Obviously, the closer the finger is to the temperature-sensitive paper, the more obvious the normalized resistance of the temperature-sensitive paper changes. Even if the distance was $5 \mathrm{~mm}$, the proximity of the finger $\left(\sim 36.5^{\circ} \mathrm{C}\right)$ couold also be detected and kept relatively stable (Figure $5 \mathrm{~b}$ ), which proved the practical application potential of the sensing paper as a noncontact control humanmachine interaction interface. Generally, the response time of temperature sensors usually takes several minutes, which is determined by the thermal conductivity of the materials and the air. Figure $5 \mathrm{c}$ shows that once the temperature-sensitive paper was placed $5 \mathrm{~mm}$ over a heating plate $\left(50{ }^{\circ} \mathrm{C}\right)$, its normalized resistance decreases rapidly. Although the resistance value reaches stable needing about $32 \mathrm{~s}$, the obvious resistance change in a short period of time was sufficient for noncontact human-machine interaction interface. More importantly, the temperature-sensitive paper had stable sensing performance, proven by the good temperature response behavior during repeatedly tested in 28 and $50{ }^{\circ} \mathrm{C}$ environment test (Figure $5 \mathrm{~d}$ ), and by the not obvious difference in the sensitivity and response time of the same sensor between Day 1 and Day 30 (Figure 5e,f).
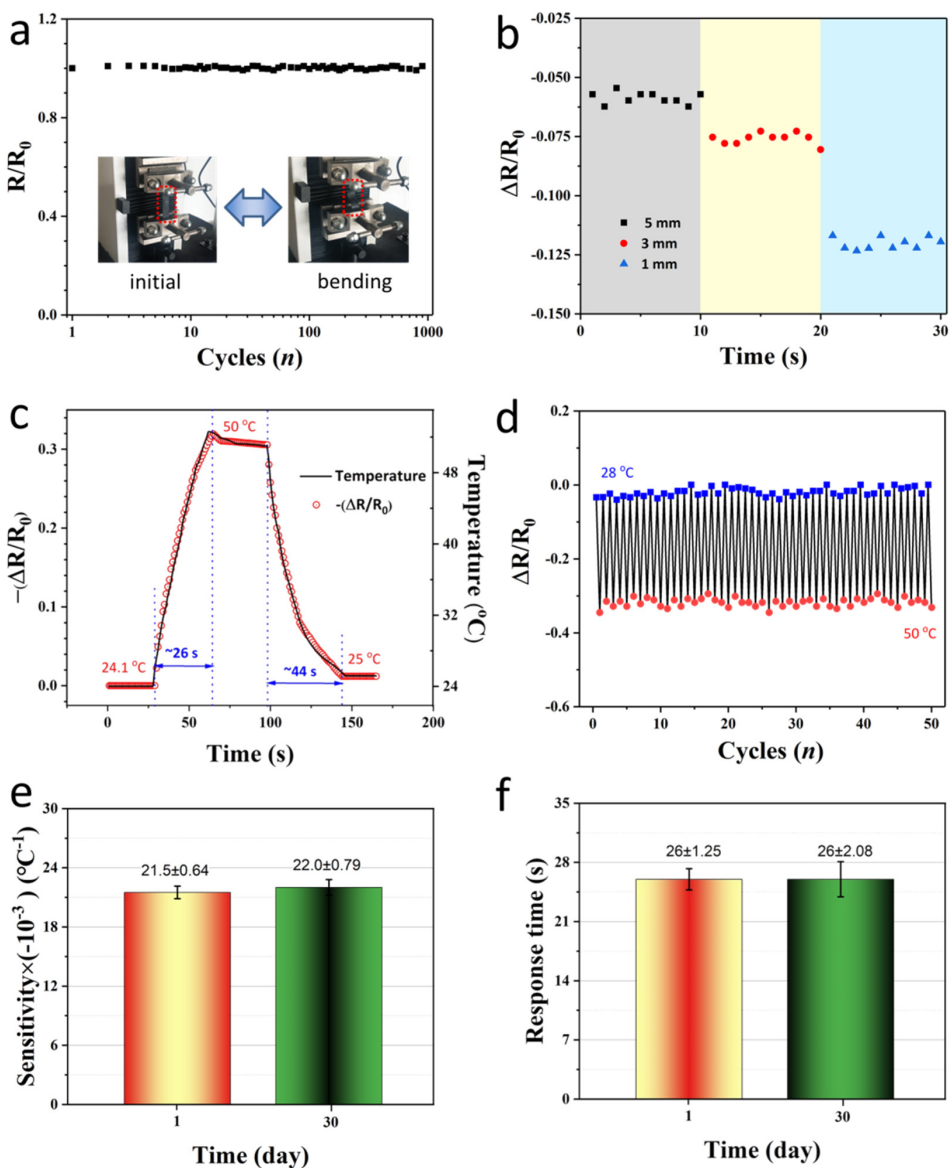

Figure 5. Temperature-sensitive performances. (a) Sensing stability of PEDOT:PSS paper buckled from initial to $-30 \%$ for 1000 times; (b) Temperature sensitivity of the PEDOT:PSS paper at a finger proximity distances of 1,3 , and $5 \mathrm{~mm}$, respectively; (c) The response time curve ranges from $28{ }^{\circ} \mathrm{C}$ to $50{ }^{\circ} \mathrm{C}$; (d) Multi-cycles temperature-sensing stability tested between 28 and $50{ }^{\circ} \mathrm{C}$. Comparison of (e) sensitivity and (f) response time of the same sensor between Day 1 and Day 30.

\section{Applications}

The above research shows that the prepared flexible temperature sensor has the advantages of high sensitivity, good flexible, fast response time, and good stability. Combined with the characteristics of simple and large-area preparation, it meets the application 
requirements of electronic skin, intelligent robot, human-machine interaction interface and other fields. To verify its practical applicability, we integrate the above-mentioned temperature-sensitive paper to a temperature sensing array with $3 \times 2$ pixels, which acts as a noncontact human-machine interacting interface to control smart vehicle and computer game. The schematic and optical images of the temperature sensing-based control interface are shown in Figure $6 a, b$, respectively. The designed computer game interface of ground mouse is shown in Figure 6c, which can collect the temperature value of each sensing pixel and responds to it, and the higher the detected proximity temperature, the darker the color of the corresponding square. During gaming, the computer interface will randomly pop out of two different colored squares (light red scores five points and dark red scores ten points). One finger of the player needs to get close to the correct sensing pixel and control the distance between the two to get the correspondence scores. Once the finger accidentally approaches other sensing pixels or touches any sensing pixel, a result "error" is displayed. This game can strengthen the player's hand control ability and is especially suitable as a fun rehabilitation game for patients with hand dyskinesia. The temperature-sensitive array prepared as shown in Figure $6 \mathrm{~d}$ can also be used as a noncontact interface to control the movement of the Bluetooth car and realize noncontact human-machine interaction. The six pixels on the sensor array can successfully control the forward, backward, left turn, right turn, and gear shift of the Bluetooth car. In addition to controlling various games, the sensor is also suitable for the control of various public equipment (e.g., elevators and led lights) to reduce the probability of cross-infection during the COVID-19 epidemic. The above experiments show that the flexible temperature-sensitive paper based on PEDOT:PSS has high sensitivity and good stability to detect nearby temperature changes and has promising prospects in artificial intelligence interactive applications in "noncontact" scenarios.

a

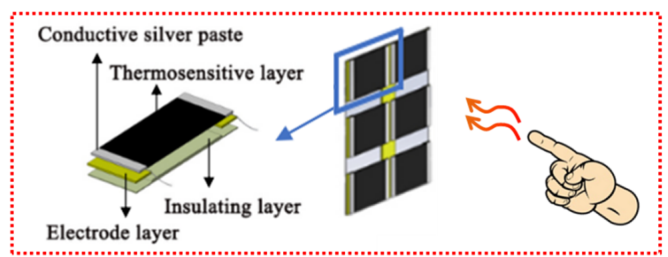

C

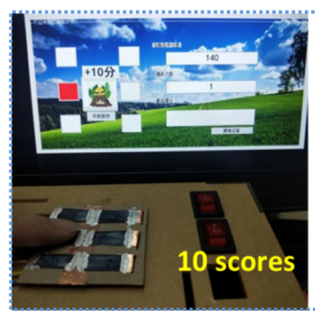

$d$

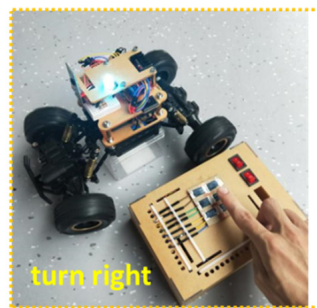

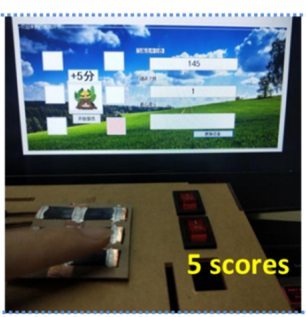

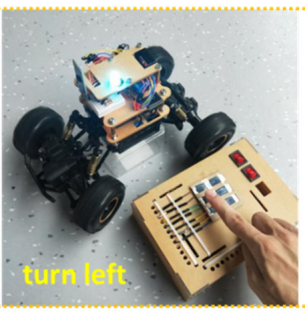

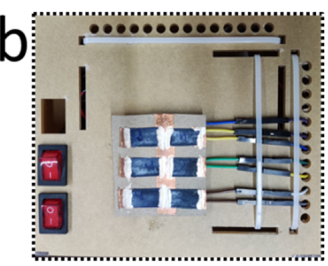
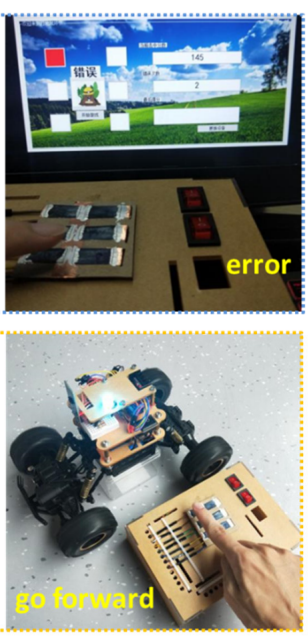

Figure 6. Applications of the flexible PEDOT:PSS temperature-sensitive paper as a noncontact human-machine interface to realize the interaction between player and "Pound-A-Mole" game and a Bluetooth car. (a) Schematically illustrating the configuration of the PEDOT:PSS based temperature sensor; (b) Optical image of the temperature sensing-based control interface. Application demos of (c) "Pound-A-Mole" game and (d) Bluetooth car demonstrating the realization of noncontact human-machine control by a temperature sensing-based interface. 


\section{Conclusions}

In summary, we fabricated a noncontact flexible temperature sensor via a simple dip-drying progress, combining the sensitive temperature-responsive property of the PEDOT:PSS with the good hygroscopicity of the printer paper, the temperature-sensitive paper show a good sensing performance including high sensitivity, quick response and good stability within the temperature range of $20-50{ }^{\circ} \mathrm{C}$. To prove the practicability of the noncontact temperature sensor, a $3 \times 2$ sensing array was prepared as a noncontact human-machine interface to realize the interaction between player and "Pound-A-Mole game" and a Bluetooth car. These two demos show the sensor's ability to perceive changes in temperature, verifying its application potential as a noncontact human-machine interaction interface.

Author Contributions: Conceptualization, Y.Z., X.Y. and B.H.; methodology, S.C. and X.H.; writingoriginal draft, S.C. and P.H.; writing-review and editing, X.H. and P.H.; supervision, Y.Z., X.Y., and B.H.; All authors have read and agreed to the published version of the manuscript.

Funding: This research was funded by "Study on One-Step Construction of Capacitive Ionic Skins via 3D Printing and Its Key Technology", grant number 52103025.

Institutional Review Board Statement: Not applicable.

Informed Consent Statement: Not applicable.

Data Availability Statement: Not applicable.

Acknowledgments: This publication is the result of the implementation of the following project: NSFC NO.: 52103025 "Study on one-step construction of capacitive ionic skins via 3D printing and its key technology".

Conflicts of Interest: The authors declare no conflict of interest.

\section{References}

1. Cheng, X.; Zhang, F.; Bo, R.; Shen, Z.; Pang, W.; Jin, T.; Song, H.; Xue, Z.; Zhang, Y. An anti-fatigue design strategy for 3D ribbon-shaped flexible electronics. Adv. Mater. 2021, 33. [CrossRef] [PubMed]

2. Milosevic, B.; Leardini, A.; Farella, E. Kinect and wearable inertial sensors for motor rehabilitation programs at home: State of the art and an experimental comparison. Biomed. Eng. Online 2020, 19, 25. [CrossRef]

3. Huang, K.; Liu, B.; Mostafa, O.; Qiu, D.; Yang, H. Accurate Flexible Temperature Sensor Based on Laser-Induced Graphene Material. Shock. Vib. 2021, 2021, 9938010. [CrossRef]

4. Zhu, C.; Chortos, A.; Wang, Y.; Pfattner, R.; Lei, T.; Hinckley, A.C.; Pochorovski, I.; Yan, X.; To, J.W.-F.; Oh, J.Y.; et al. Stretchable temperature-sensing circuits with strain suppression based on carbon nanotube transistors. Nat. Electron. 2018, 1, 183-190. [CrossRef]

5. Yu, Y.; Peng, S.; Blanloeuil, P.; Wu, S.; Wang, C.H. Wearable temperature sensors with enhanced sensitivity by engineering microcrack morphology in PEDOT:PSS-PDMS sensors. ACS Appl. Mater. Interfaces 2020, 12, 36578-36588. [CrossRef]

6. Putnam, K. Prevention of unplanned patient hypothermia. Aorn. J. 2015, 102, 10-12.

7. Monteiro, F.L.J.; Halpern, H.; Bortoli, F.; Kataoka, L.; Marumo, C.; Ribeiro, M.; Castellassi, M.; Mendes, C.; Wolosker, N. Forced-air warming in patients undergoing endovascular procedures: Comparison between 2 thermal blanket models. Ann. Vasc. 2018, 47, 98-103. [CrossRef]

8. Kumari, P.; Mathew, L.; Syal, P. Increasing trend of wearables and multimodal interface for human activity monitoring: A review. Biosens. Bioelectron. 2017, 90, 298-307. [CrossRef] [PubMed]

9. Bae, G.Y.; Pak, S.W.; Kim, D.; Lee, G.; Kim, D.H.; Chung, Y.; Cho, K. Linearly and highly pressure-sensitive electronic skin based on a bioinspired hierarchical structural array. Adv. Mater. 2016, 28, 5300-5306. [CrossRef] [PubMed]

10. Michael, W.; Truby, R.L.; Fitzgerald, D.J.; Mosadegh, B.; Whitesides, G.M.; Lewis, J.A.; Wood, R.J. An integrated design and fabrication strategy for entirely soft, autonomous robots. Nature 2016, 536, 451-455.

11. Hong, S.; Lee, S.; Kim, D.-H. Materials and Design Strategies of Stretchable Electrodes for Electronic Skin and its Applications. Proc. IEEE 2019, 107, 2185-2197. [CrossRef]

12. Trung, T.; Lee, N. Flexible and stretchable physical sensor integrated platforms for wearable human-activity monitoring and personal healthcare. Adv. Mater. 2016, 28, 4338-4372. [CrossRef]

13. Rogers, J.A. Wearable electronics: Nanomesh on-skin electronics. Nat. Nanotechnol. 2017, 12, 839-840. [CrossRef] [PubMed]

14. Chortos, A.; Liu, J.; Bao, J.L.Z. Pursuing prosthetic electronic skin. Nat. Mater. 2016, 15, 937-950. [CrossRef]

15. Tao, X.; Jia, H.; He, Y.; Liao, S.; Wang, Y. Ultrafast Paper Thermometers Based on a Green Sensing Ink. ACS Sens. 2017, 2, $449-454$. [CrossRef] [PubMed] 
16. Weiss, N.O.; Zhou, H.; Liao, L.; Liu, Y.; Jiang, S.; Huang, Y.; Duan, X. Graphene: An Emerging Electronic Material. Adv. Mater. 2012, 24, 5782-5825. [CrossRef]

17. Yu, C.; Kim, Y.S.; Kim, D.; Grunlan, J. Thermoelectric Behavior of Segregated-Network Polymer Nanocomposites. Nano Lett. 2008, 8, 4428-4432. [CrossRef]

18. Chen, Y.; Lu, B.; Chen, Y.; Feng, X. Breathable and stretchable temperature sensors inspired by skin. Sci. Rep. 2015, 5, 11505. [CrossRef]

19. Matsuhisa, N.; Inoue, D.; Zalar, P.; Jin, H.; Matsuba, Y.; Itoh, A.; Yokota, T.; Hashizume, D.; Someya, T. Printable elastic conductors by in situ formation of silver nanoparticles from silver flakes. Nat. Mater. 2017, 16, 834-840. [CrossRef]

20. Lv, D.; Chen, W.; Shen, W.; Peng, M.; Zhang, X.; Wang, R.; Xu, L.; Xu, W.; Song, W.; Tan, R. Enhanced flexible room temperature ammonia sensor based on PEDOT: PSS thin film with FeCl3 additives prepared by inkjet printing. Sens. Actuators B: Chem. 2019, 298, 126890. [CrossRef]

21. Yang, B.; Wang, C.; Xiao, R.; Yu, H.; Wang, J.; Liu, H.; Xia, F.; Xiao, J. High sensitivity and fast response sensor based on sputtering Au tuned ZnFe2O4-SE for low concentration NH3 detection. Mater. Chem. Phys. 2020, 239, 122302. [CrossRef]

22. Algün, G.; Akçay, N. Enhanced sensing characteristics of relative humidity sensors based on Al and F co-doped ZnO nanostructured thin films. J. Mater. Sci. Mater. Electron. 2019, 30, 16124-16134. [CrossRef]

23. Lee, C.-P.; Lai, K.-Y.; Lin, C.-A.; Li, C.-T.; Ho, K.-C.; Wu, C.-I.; Lau, S.-P.; He, H.-J. A paper-based electrode using a graphene dot/PEDOT:PSS composite for flexible solar cells. Nano Energy 2017, 36, 260-267. [CrossRef]

24. Trifigny, N.; Kelly, F.M.; Cochrane, C.; Boussu, F.; Koncar, V.; Soulat, D. PEDOT:PSS-Based Piezo-Resistive Sensors Applied to Reinforcement Glass Fibres for in Situ Measurement during the Composite Material Weaving Process. Sensors 2013, 13, 10749-10764. [CrossRef] [PubMed]

25. Jonas, F.; Kraft, W. New Polythiophene Dispersions, Their Preparation and Their Use. Patent No. EP0440957B1, 27 March 1996.

26. Rivnay, J.; Inal, S.; Collins, B.; Sessolo, M.; Stavrinidou, E.; Strakosas, X.; Tassone, C.; Delongchamp, D.M.; Malliaras, G. Structural control of mixed ionic and electronic transport in conducting polymers. Nat. Commun. 2016, 7, 11287. [CrossRef] [PubMed]

27. Azar, M.G.; Dodda, J.M.; Bělský, P.; Šlouf, M.; Vavruňková, V.; Kadlec, J.; Remiš, T. Tough and flexible conductive triple network hydrogels based on agarose/polyacrylamide/polyvinyl alcohol and poly(3,4-ethylenedioxythiophene):polystyrene sulfonate. Polym. Int. 2021, 70, 1523-1533. [CrossRef] 